\title{
THE LIQUID HELIUM CRYOGENIC SYSTEM FOR THE SUPERCONDUCTING CAVITY IN SRRC
}

\author{
F. Z. Hsiao, M. C. Lin, Ch. Wang, D. S. Lee, and J. R. Chen, SRRC, Hsinchu, Taiwan \\ B. Hilbert, and A. Praud, Air Liquide DTA, Sassenage, France
}

\begin{abstract}
A $500 \mathrm{MHz}$ superconducting cavity will replace the current copper cavity and begin to operate in the beginning of the year 2003. A liquid helium cryogenic system provides the cavity at $4.5 \mathrm{~K}$ a cooling capacity of $255 \mathrm{~W}$ without LN2 pre-cooling and a liquefaction rate of 110 liter/hour with LN2 pre-cooling. A safety factor of 1.5 is used to estimate the heat load from the superconducting cavity and the heat loss from the transfer lines. With the LN2 pre-cooling, this cooling system provides a cooling capacity of up to $450 \mathrm{~W}$ to cool down the additional superconducting Landau cavity. The capacity of the system can be tuned using a frequency driver installed at the compressor station. The pressure fluctuations of the dewar and of the suction line are kept to the same stability requirement that of the cavity cryostat to minimize the influence in cavity operation. A shutdown period for maintenance of more than 8000 hours for the cryogenic system is expected without interfering with the continuous operation of the superconducting cavity.
\end{abstract}

\section{INTRODUCTION}

To improve the brightness and beam stability of the storage ring, SRRC will replace the current copper cavity with a $500 \mathrm{MHz}$ superconducting cavity and then increase the beam current to up to $400 \mathrm{~mA}$. This is the first usage of a superconducting cavity in the synchrotron light source. The cavity will be operational in the beginning of the year 2003. A liquid helium cryogenic system

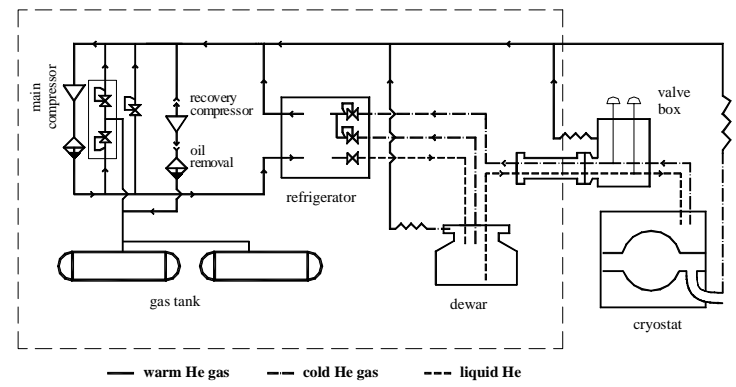

Figure 1: Configuration of the Air Liquide designed helium cryogenic system.

provides the required $4.5 \mathrm{~K}$ cooling capacity to the superconducting cavity. This system will be a turnkey system, which is designed and manufactured by the Advanced Technology Division of Air Liquide.

\section{CONFIGURATION}

Figures 1 and 2 show the configuration and the physical location of the cryogenic system respectively. The system consists of one $315 \mathrm{KW}$ main compressor, one $45 \mathrm{KW}$ recovery compressor, one $10 \mathrm{KW}$ refrigerator (cold box), one $2000 \mathrm{~L}$ dewar, two $100 \mathrm{~m}^{3}$ gas helium storage tanks, and one $6 \mathrm{~m}$ LN2-shielded multi-channel transfer line. The piping of the warm helium gas, which connects the main compressor and the refrigerator, includes one 2.5inch discharge line and one 8-inch suction line. One 2.5inch make up line is used to connect the helium tank and the control valves, which are placed near the compressor.

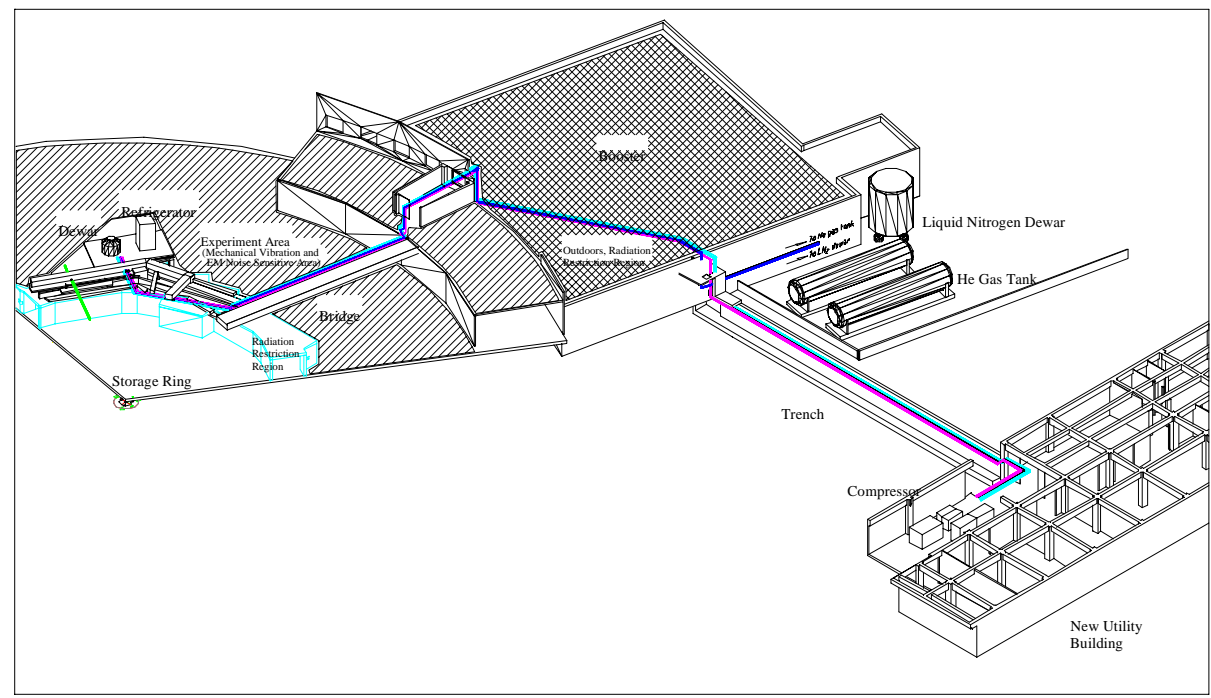

Figure 2: Location of the cryogenic system. 
Table 1 Heat load estimation

\begin{tabular}{|l|c|c|}
\hline Cryostat & Phase I & Phase II \\
\hline Distribution Box (DB) & $\begin{array}{c}80 \mathrm{~W}+0.18 \mathrm{~g} / \mathrm{s} \\
(\sim 100 \mathrm{~W})\end{array}$ & $\begin{array}{c}2 *(80 \mathrm{~W}+0.18 \mathrm{~g} / \mathrm{s}) \\
(\sim 200 \mathrm{~W})\end{array}$ \\
\hline $\begin{array}{l}\text { Transfer Line Between DB and } \\
\text { Cryostat }\end{array}$ & $10 \mathrm{~W}$ & $10 \mathrm{~W}$ \\
\hline $\begin{array}{l}\text { Transfer Line Between Dewar } \\
\text { and DB }\end{array}$ & $10 \mathrm{~W}$ & $15 \mathrm{~W}+30 \mathrm{~W}$ \\
\hline Reserved Cryogenic Capacity & $35 \mathrm{~W}($ heater $)$ & $35 \mathrm{~W}$ (heater) \\
\hline Total & $150 \mathrm{~W}+0.18 \mathrm{~g} / \mathrm{s}$ & $260 \mathrm{~W}+0.36 \mathrm{~g} / \mathrm{s}$ \\
\hline Total*Safety Factor & $225 \mathrm{~W}+0.27 \mathrm{~g} / \mathrm{s}$ & $390 \mathrm{~W}+0.54 \mathrm{~g} / \mathrm{s}$ \\
\hline Total equivalent cooling power & $255 \mathrm{~W}$ & $450 \mathrm{~W}$ \\
\hline
\end{tabular}

Safety Factor $=1.5$

Both the discharge and the suction lines are $160 \mathrm{~m}$ in length; the make up line is $120 \mathrm{~m}$. The liquid helium line between the refrigerator and the dewar is $5 \mathrm{~m}$. This line is thermal shielded with the cold helium gas from the dewar to the refrigerator. The liquid helium will be drawn off from the dewar and sent to the distribution valve box through the multi-channel transfer line, then the helium is sent to the cryostat of the superconducting cavity through the flexible transfer line. A nitrogen storage tank with a capacity of 20000L will be installed at the site of the helium tanks to provide liquid nitrogen to the refrigerator for pre-cooling. Liquid nitrogen is also used to thermal shield the cavity cryostat. A transfer line of 1 inch in diameter, $120 \mathrm{~m}$ in length is used to transfer liquid nitrogen.

The refrigerator and the dewar are located on a platform close to the distribution box and the cavity so that the transfer heat loss can be minimized. Since the refrigerator uses the expansion turbines, no vibrations during the beam operation will be expected. The large power compressor is located $80 \mathrm{~m}$ straight from the storage ring to reduce the vibration effects on the beam orbit. The cryogenic system will be ready at the end of the year 2002 .

\section{SYSTEM DESIGN}

\subsection{Heat Load}

Estimation of the system heat load is shown in Table 1 [1]. The estimated heat load is $100 \mathrm{~W}$ for one cavity, $10 \mathrm{~W}$ for the valve box, $15 \mathrm{~W}$ for the $10 \mathrm{~m}$ flexible transfer lines, $10 \mathrm{~W}$ for the multi-channel transfer line, and $35 \mathrm{~W}$ for the reserved cooling capacity. Calculated with a safety factor of 1.5, this cryogenic system will provide a cooling capacity of $255 \mathrm{~W}$ at $4.5 \mathrm{~K}$ without liquid nitrogen precooling. Since the $1.5 \mathrm{GHz}$ superconducting Landau cavity will be installed in the storage ring in the future, this system is to provide a cooling capacity of $450 \mathrm{~W}$ at $4.5 \mathrm{~K}$ at phase II of the project. The capacity of $450 \mathrm{~W}$ is estimated based on the additional heat load of $100 \mathrm{~W}$ from the Landau cavity and that of $30 \mathrm{~W}$ from the additional transfer lines. In addition to the cooling capacity for phases I and II, the system needs to provide a helium liquefaction rate of 110 liters/hour to cool down the cavity from room temperature to $4.5 \mathrm{~K}$. The cooling of the cavity and the refrigerator will be done separately. During cavity cooling, the refrigerator will not use the enthalpy of the cold helium gas from the cavity. Instead, the cold gas

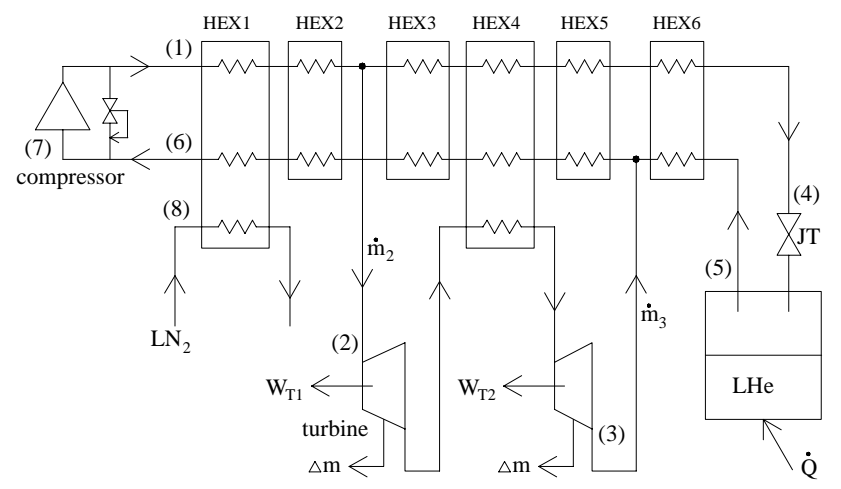

(a) flow chart

\begin{tabular}{|l|l|l|l|l|l|}
\hline & $\dot{\mathrm{m}}(\mathrm{g} / \mathrm{s})$ & $\mathrm{P}(\mathrm{b} a r)$ & $\mathrm{T}(\mathrm{K})$ & $\mathrm{h}(\mathrm{J} / \mathrm{g})$ & $\mathrm{s}(\mathrm{J} / \mathrm{g}-\mathrm{K})$ \\
\hline$(1)$ & 48.2 & 12.05 & 318 & 1656 & 24.78 \\
\hline$(2)$ & 26.2 & 11.77 & 67.9 & 355 & 16.79 \\
\hline$(3)$ & 26.0 & 1.25 & 10.5 & 52 & 11.62 \\
\hline$(4)$ & 22.1 & 11.73 & 5.0 & 2 & 1.484 \\
\hline$(5)$ & 22.1 & 1.25 & 4.5 & 15 & 6.174 \\
\hline$(6)$ & 48.0 & 1.15 & 313 & 1624 & 29.66 \\
\hline$(7)$ & 51.2 & 1.05 & 318 & 1652 & 29.85 \\
\hline$(8)$ & 0 & - & - & - & - \\
\hline
\end{tabular}

(b) state at phase I

\begin{tabular}{|l|l|l|l|l|l|}
\hline & $\dot{\mathrm{m}}(\mathrm{g} / \mathrm{s})$ & $\mathrm{P}(\mathrm{bar})$ & $\mathrm{T}(\mathrm{K})$ & $\mathrm{h}(\mathrm{J} / \mathrm{g})$ & $\mathrm{s}(\mathrm{J} / \mathrm{g}-\mathrm{K})$ \\
\hline$(1)$ & 70.9 & 14.75 & 318 & 1657 & 24.360 \\
\hline$(2)$ & 32.9 & 14.30 & 60.1 & 315 & 15.744 \\
\hline$(3)$ & 32.7 & 1.30 & 10.2 & 51 & 11.373 \\
\hline$(4)$ & 38.0 & 14.22 & 4.7 & 2 & 1.164 \\
\hline$(5)$ & 38.0 & 1.30 & 4.5 & 15 & 6.104 \\
\hline$(6)$ & 70.7 & 1.10 & 311 & 1615 & 29.633 \\
\hline$(7)$ & 73.9 & 1.05 & 318 & 1652 & 29.847 \\
\hline$(8)$ & 3.6 & 1.25 & 79.2 & -118 & 2.888 \\
\hline
\end{tabular}

(c) state at phase II

Figure 3: Thermodynamic state of the refrigerator.

will be heated to room temperature and then injected to the warm suction line.

\subsection{Thermodynamic State}

The design of the refrigerator is shown in Figure 3 [2]. The work cycle of the refrigerator is based on the modified Claud cycle. The high inlet temperature attributes to the system installed within the subtropics area. The outlet temperature of the JT valve is defined at $4.5 \mathrm{~K}$ because the cavity will be operated at $4.5 \mathrm{~K}$. Two expansion turbines, one warm turbine and one cold turbine, are connected in series. The turbines remove most of the energy of the gas stream. The temperature of the helium gas after passing through the warm turbine decreases to around $50 \mathrm{~K}$. It is then cooled down in the heat exchanger (HEX) 4 to a temperature lower than 16K and expanded in the cold turbine from which it exits at about 10K. The helium gas is then returned at a low pressure through heat exchangers where it cools down the high-pressure helium in heat exchangers 3,4 and 5. The calculated cooling capacities for the first and second phases are $270 \mathrm{~W}$ and $470 \mathrm{~W}$ respectively [3]. These values meet the capacity requirement specified in Table1. The consumption of the liquid nitrogen at phase II is 3.6 g/s, i.e., $16.2 \mathrm{~L} / \mathrm{Hr}$. 


\subsection{Helium Flow Process}

To maintain a stable operation of the cavity, we keep the variation of the helium level of the cryostat at less than $\pm 1 \%$ and the variation of pressure at less than \pm 3 mbar. Since the heat load of the cavity cryostat fluctuates from $35 \mathrm{~W}$ at the condition of standby to the maximum $100 \mathrm{~W}$ at a full operation, a heater in the cryostat is used to maintain a constant heat load of $100 \mathrm{~W}$. In addition, the helium flow is remote controlled by the actuated cryogenic valves in the distribution valve box.

The control system of the cryogenic system is independent from the one for the cavity and the distribution box. Only some status is communicated between these two control systems. The cycle high pressure is controlled by the feed and discharge control valves, which are mounted on the downstream side of the oil removal module. These two valves are operated by a PID control loop so that the storage tanks supply the additional helium in case of a pressure decrease, and store the surplus helium in case of a pressure increase. Feeding and bleeding both utilize the single make-up line. The pressure fluctuation of the dewar and the compressor suction line is kept close to the same stability level of the cavity cryostat to minimize its influence on cavity operation. The dewar pressure is controlled by a return pressure control valve in the refrigerator. In addition, a heater in the dewar will provide the freedom to fine-tune the surplus cooling capacity. The suction pressure of the compressor is persistently maintained at 1.05 bar, which is slightly above the local atmospheric pressure. This pressure is controlled by the bypass valve, which connects the discharge line and the suction line.

The same cryogenic system must meet the specified capacity in phases I and II. In addition to the usage of liquid nitrogen to pre-cool the helium flow, both the compressor and the refrigerator must match the different condition of the mass flow rate in these two phases. The main compressor processes a maximum flow rate of 85 $\mathrm{g} / \mathrm{s}$, which exceeds the maximum design value specified in Figure 3. Instead of a sliding valve, the compressor uses a frequency driver, with a rated power $315 \mathrm{~kW}$, to regulate the process flow rate. The driving motor of the compressor package can thus be driven between $20 \mathrm{~Hz}$ and $60 \mathrm{~Hz}$ such that the minimum flow rate is $28 \mathrm{~g} / \mathrm{s}$. The expansion turbine has a smaller range of adjusting capacity of mass flow rate, compared to that of the compressor. By changing the rotating speed, the expansion turbine can process more/less helium mass flow when the cycle high-pressure increases/decreases.

\subsection{Long Period Operation}

The duty period is crucial to this cryogenic system. Continuous operation is guaranteed by using highly reliable components such as the industrial oil lubricated screw compressor, the static gas bearing suspended expansion turbines, and the solid-state electronic components. For maintenance, a shutdown period of more than 8000 hours is required without interfering with the continuous operation of the superconducting cavity. Major components need some care including the adsorber in the refrigerator, the charcoal in the oil removal system, and the bearing of the cooling fan for the motor of the main compressor.

The duty period of the activated charcoal in the oil removal system can be increased if the Grade A helium gas with a purity of $99.995 \%$ is used in the cryogenic system. The bearing of the cooling fan lasts for 8000 hours if the ambient temperature is controlled within $35^{\circ} \mathrm{C}$. Two cryogenic adsorbers at $80 \mathrm{~K}$ and one cryogenic adsorber at $20 \mathrm{~K}$ are installed inside the refrigerator. The two $80 \mathrm{~K}$ adsorbers are connected in parallel and will switch automatically when one is saturated and needs to be regenerated. All the regeneration and the re-cooling are processed under a cold condition. Therefore, the operation of the refrigerator is not affected by the regeneration of the $80 \mathrm{~K}$ adsorber.

An emergence power will automatically supply the refrigerator and keep the control system operating to minimize the helium loss in case of electricity failures. Since the emergency power system is not sufficient to supply the compressor, a small power recovery compressor is used instead. This recovery compressor will compress both the helium gas from the cryostat and the one remained in the piping into the storage gas tanks. A pressure regulation device at the suction side of the recovery compressor regulates the suction pressure. Thus even if the pressure in the circuits is above the acceptable level of the recovery compressor, the helium can still be restored into the two storage tanks.

\section{CONCLUSION}

A liquid helium cryogenic system for the superconducting cavity has been designed. The main features of this system are the changeable cooling capacity from $255 \mathrm{~W}$ to $450 \mathrm{~W}$, the liquefaction rate of 110 liter/hour, the high process inlet temperature $318 \mathrm{~K}$, the specified process outlet temperature $4.5 \mathrm{~K}$, the stable pressures of the suction line and the dewar, and the long duty period operation.

\section{REFERENCES}

[1] "Technical Specification of the Main Cryogenic Plant for a 500MHz SRF Module," SRRC Technical Report, Nov. 24, 2000.

[2] A. Praud and B. Hilbert, "Technical Proposal: Helium Refrigerator System for SRRC," by the Advanced Technology Division (DTA) of Air Liquide, January 2001.

[3] S.W. Van Sciver, "Helium Cryogenics,"Plenum Press, 1986, p.295. 